\title{
LETTER
}

\section{Beneficial acclimation and the Bogert effect}

Elrike Marais* and Steven L. Chown

Centre for Invasion Biology,

Department of Botany and

Zoology, Stellenbosch

University, Private Bag X1, Matieland, 7602, Stellenbosch, South Africa

*Correspondence: E-mail:

emarais@sun.ac.za

\begin{abstract}
Few studies have examined the extent to which phenotypic plasticity in a given trait might be influenced by behavioural responses to an environmental cue. Regulatory behaviour might eliminate environmental variation such that little selection for physiological change would take place. Here, to test this Bogert effect on acclimation, we use two life-stages of a kelp fly that inhabit the same habitat, but differ profoundly in their behaviour. We predicted that when denied opportunities for behavioural regulation, mobile, though brachypterous adults would show a performance advantage in most thermal environments following acclimation to their preferred temperature(s). By contrast, in the less mobile larvae, that have a broader thermal preference, beneficial acclimation would be more evident. Ordered factor ANOVA with orthogonal polynomial contrasts revealed that adults recovered faster from chill coma following any one of six short-term temperature treatments if they had been acclimated at low temperature, whilst larvae showed beneficial acclimation.
\end{abstract}

\section{Keywords}

Acclimation, behaviour, chill coma recovery, ontogeny, phenotypic plasticity.

\section{INTRODUCTION}

Physiologists have long maintained that phenotypic plasticity is adaptive. In advance of or in response to a change in the environment, organisms are able to alter aspects of their physiology such that they will be better able to survive that change. Evidence for such adaptive phenotypic plasticity has typically come from seasonal responses to cold, heat or water stress (Prosser 1986; Chown \& Nicolson 2004). More recently, the extent to which phenotypic plasticity following short-term acclimation can be considered beneficial has been questioned. Several empirical studies have demonstrated that exposure to a given environment does not necessarily provide an organism with a performance advantage in that environment relative to those organisms that have not experienced it (e.g. Leroi et al. 1994; Gilchrist \& Huey 2001; Stillwell \& Fox 2005; Deere \& Chown 2006). In consequence, it has been suggested that beneficial acclimation is uncommon, and that explicit tests for alternative responses, such as optimal temperatures or deleterious acclimation, should always be undertaken (Huey \& Berrigan 1996; Huey et al. 1999; Wilson \& Franklin 2002).

These proposals have refocused attention on those circumstances under which adaptive phenotypic plasticity might be likely (Ghalambor et al. 2007), and when acclimation might be beneficial (Chown \& Terblanche 2007;
Loeschcke \& Hoffmann 2007). Accordingly, selection should favour plasticity when environmental variability is high, environments produce reliable cues to which organisms are capable of responding, different phenotypes are favoured in different environments, the costs of plasticity are low, and dispersal among populations is high. Considerable attention is now being given to many of these questions (e.g. Zeilstra \& Fischer 2005; Rako \& Hoffmann 2006; Ghalambor et al. 2007; Kristensen et al. 2007; Van Kleunen \& Fischer 2007). However, empirical explorations of the effects of cue reliability, i.e. both the variability of the environmental parameter of significance and the predictability of that variation, are less common. Although attention has been given periodically to the significance of environmental predictability and the way in which it should be measured (Levins 1968; Kingsolver \& Huey 1998), and theoretical approaches continue to investigate its significance, empirical characterizations of the form of environmental variation and the direction of, and extent to which it elicits, phenotypic plasticity remain scarce (see Chown \& Terblanche 2007 for review). Moreover, even fewer investigations have considered the extent to which behavioural responses to a given cue might influence the likelihood of the evolution of other phenotypic responses.

Behaviour has long been considered a driver of evolutionary change, such that changes in behaviour expose an 
organism to novel environments, which in turn exert selection for changes in other traits. However, behaviour might also inhibit evolutionary change by buffering the effects of the environment (Hertz \& Huey 1981; Parsons 1998; Huey et al. 2003). It was Bogert (1949) who first argued that regulatory behaviour might eliminate environmental variation to such an extent that little selection for physiological change would take place. Such behavioural inertia has since been termed the 'Bogert effect' (Huey et al. 2003; see also Bartholomew 1958; Bradshaw 1972 for related discussions). In the context of phenotypic plasticity, it is clear that behaviour might likewise act to minimize the extent of environmental variability experienced by an organism, thus reducing or perhaps eliminating the response shown by other aspects of the phenotype. For example, in response to a warmer temperature, an organism could simply seek out a cooler microclimate, rather than alter its physiology to perform better under the changed circumstances.

Moreover, at least in those taxa where life stages differ substantially in behaviour, the Bogert effect might lead to considerable dissimilarity among stages (or age classes) in the extent to which adaptive phenotypic plasticity or beneficial acclimation is significant (Huey 1991). In Drosophila, for example, adults are highly mobile and larvae much less so (Feder et al. 2000). Moreover, female oviposition site selection largely determines the larval thermal environment (Feder et al. 1997). In consequence, it might be expected that adults should show much less evidence of beneficial acclimation than should larvae. Similar, stage-related differences can be expected for a wide range of invertebrates in which stages differ in their mobility (e.g. gall insects, leaf miners). However, to date, few studies have thought to examine the implications of the Bogert effect for the likelihood of beneficial acclimation, and fewer still have used stage-related differences in behaviour as a model system to do so.

In this study we do so, using an a priori, strong-inference approach to examine the extent to which chill-coma recovery time (Gibert et al. 2001) varies in a way inconsistent either with the beneficial acclimation hypothesis, or its alternatives (Huey \& Berrigan 1996; Deere \& Chown 2006), in two life stages of a brachypterous kelp fly species. Adults and larvae of Paractora dreuxi inhabit the same macroenvironment, but differ profoundly in the extent to which they can behaviourally regulate their position within it (Crafford 1984; Klok \& Chown 2001; Terblanche et al. 2007). Therefore, we predict that, when denied opportunities for behavioural regulation, mobile adults, which have a narrow thermal preference, should show a performance advantage in most thermal environments following acclimation to the preferred temperature. By contrast, in the less mobile larvae, that have a broader thermal preference, beneficial acclimation should be more evident.

\section{MATERIALS AND METHODS}

\section{Study site and animal collection}

Paractora dreuxi Séguy (Diptera, Helcomyzidae) is distributed across several islands in the sub-Antarctic. On Marion Island (46 $\left.54^{\prime} \mathrm{S}, 37^{\circ} 45^{\prime} \mathrm{E}\right)$, all stages inhabit pebbled beaches where they remain in close association with bullkelp (Durvillaea antartica) wrack, which forms the primary resource for developing larvae (see Supporting Information for additional information on this species). For this study, larvae and adults were collected using soft tweezers or aspirators, respectively, from Trypot Beach (see Klok \& Chown 2001), during the April 2006, 2007 and 2008 (late austral summer/early autumn) four-week, resupply periods on the island. Individuals were kept in $500 \mathrm{~mL}$ plastic jars, on small pieces of kelp, at low density, and returned to the island laboratory within $2 \mathrm{~h}$. The Trypot Beach site is less than $2 \mathrm{~km}$ from the laboratory and main weather station at the island, where temperatures just below the soil surface have been logged since June 2002 (Deere et al. 2006). Nonetheless, for the duration of one sampling period, an eight channel SQ800 Squirrel (Grant Instruments, UK) data logger was placed on Trypot Beach to record microclimate temperatures at a range of substrate depths. The data logger was set to record average temperature for 5-min intervals using temperature readings obtained by $30 \mathrm{~s}$ sampling. Type $T$ 36-gauge thermocouples were connected to the data logger and thermocouple tips were attached to a pole every $10 \mathrm{~cm}$. The pole with thermocouples attached was buried to $40 \mathrm{~cm}$ below the beach surface. Remaining channels were placed on top of and under round pebbles (roughly $15-20 \mathrm{~cm}$ diameter) at surface level to obtain an estimate of surface temperature.

\section{Acclimation treatments}

At the laboratory, individuals were haphazardly sorted into $500 \mathrm{~mL}$ plastic jars at low density (adults: $n=25 /$ jar; larvae $n=50 /$ jar, adults and larvae in separate jars with more than five jars available for each treatment combination) together with moistened, fresh kelp. The containers were then randomly assigned to one of four acclimation temperatures $\left(0,5,10,15^{\circ} \mathrm{C} ; 12: 12 \mathrm{~L}: \mathrm{D}\right)$ maintained by temperaturecontrolled cabinets (LabCon, Maraisburg, South Africa), monitored hourly with thermochron iButtons (Model DS1921: mean $\pm \mathrm{SD} ; 0{ }^{\circ} \mathrm{C}:-0.1 \pm 0.6 ; 5{ }^{\circ} \mathrm{C}: 4.7 \pm 0.5$; $\left.10{ }^{\circ} \mathrm{C}: 9.3 \pm 0.3 ; 15{ }^{\circ} \mathrm{C}: 14.8 \pm 0.3\right)$. The above temperatures represent the full range of conditions likely to be encountered by the insects at sea level on Marion Island (Klok \& Chown 2001; Deere et al. 2006; Fig. 1). Previous work, on arthropods from both Marion Island and elsewhere, has indicated that a seven-day acclimation period is sufficient for the full change in the phenotype to be 


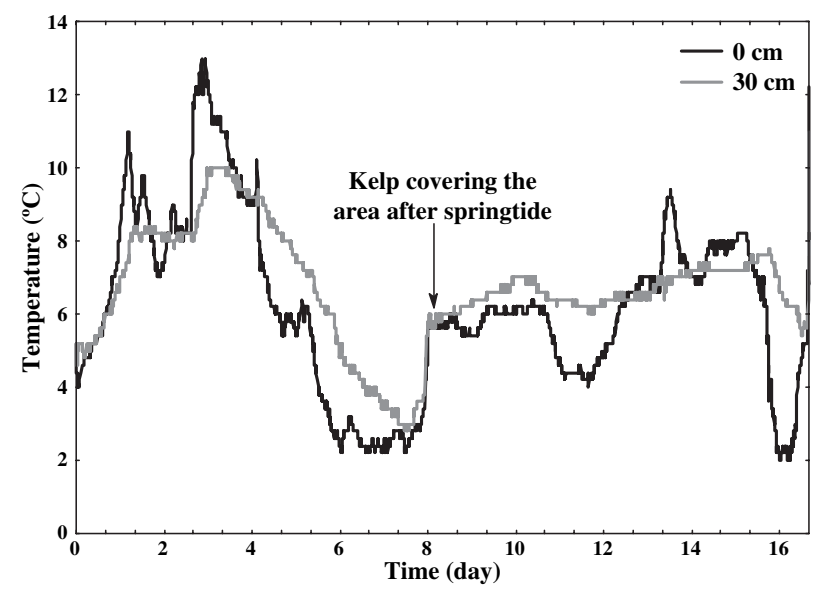

Figure 1 Microclimate data recorded at Trypot Beach in mid-April 2006 from on top of pebble substrate $(0 \mathrm{~cm})$ and $30 \mathrm{~cm}$ beneath the beach surface. The arrow indicates the point at which the area was covered with c. $30 \mathrm{~cm}$ of kelp following springtide. Additional data for April 2008 are provided in the Supporting Information.

realized (Hoffmann \& Watson 1993; Terblanche et al. 2006, 2007), and therefore flies and larvae were held at the acclimation temperatures for this period. During this time, on a daily basis, the substrate was re-moistened with fresh water and where necessary, additional kelp was added as a food source. The containers were randomized between shelves to avoid shelf effects. To ensure that acclimation did not proceed for a period longer than seven days, acclimation groups were staggered over consecutive days in a random order and all experiments were completed within the four-week periods.

\section{Treatment temperatures}

Previously it has been shown that exposure to a series of acclimation temperatures and examination of a given trait following such exposure cannot necessarily adequately distinguish between the beneficial acclimation hypothesis $(\mathrm{BAH})$ and 'colder is better', or between the BAH and 'warmer is better' (Deere et al. 2006). Rather, to determine whether '...acclimation to a particular environment gives an organism a performance advantage in that environment...' (Leroi et al. 1994), an additional series of 'test temperatures' is required which includes temperatures both similar and dissimilar to those of the acclimation temperature. Here we included $2 \mathrm{~h}$ exposures to a range of treatment temperatures to provide us with the means to distinguish the beneficial acclimation hypothesis from others. In some ways these exposures are similar to the temperature transients discussed by Dillon et al. (2007), but nonetheless fulfil the criteria for distinguishing among the acclimation hypotheses.

Thus, to estimate the extent to which acclimation enabled individuals to improve their performance during a subsequent thermal challenge, individuals from each of the acclimation groups were subject to one of six treatment temperatures in a fully crossed design (Fig. 2). These treatments constituted acute, non-lethal exposure to high $\left(25,20\right.$ and $\left.10^{\circ} \mathrm{C}\right)$ or low $\left(5,0\right.$ and $\left.-2{ }^{\circ} \mathrm{C}\right)$ temperatures for $2 \mathrm{~h}$, chosen on the basis of previous information on the critical thermal limits of both stages $\left(-5^{\circ} \mathrm{C}\right.$ and $35.5^{\circ} \mathrm{C}$ in larvae and $-2.7^{\circ} \mathrm{C}$ and $30.2^{\circ} \mathrm{C}$ in adults). The treatment temperatures were chosen specifically to assess whether acclimation to high $\left(15\right.$ and $\left.10^{\circ} \mathrm{C}\right)$ or low $\left(5\right.$ and $\left.0{ }^{\circ} \mathrm{C}\right)$
Figure 2 Schematic of the experimental design showing the acclimations and subsequent treatments used to assess phenotypic plasticity in adults and larvae of Paractora dreuxi. The acclimation temperatures are those at which adults and larvae were held for 7 days. The treatment temperatures are those to which adults and larvae from each acclimation group were exposed, for $2 \mathrm{~h}$, after the acclimation treatment. The box on the right provides the temperature for chill coma induction and the duration of exposure of adults and larvae to that temperature, and the recovery temperature at which time to recovery was measured.

$\begin{array}{cc}\text { Acclimation } & \text { Treatment } \\ \text { temperatures } & \text { temperatures } \\ \text { (7 days) } & (2 \mathrm{~h})\end{array}$

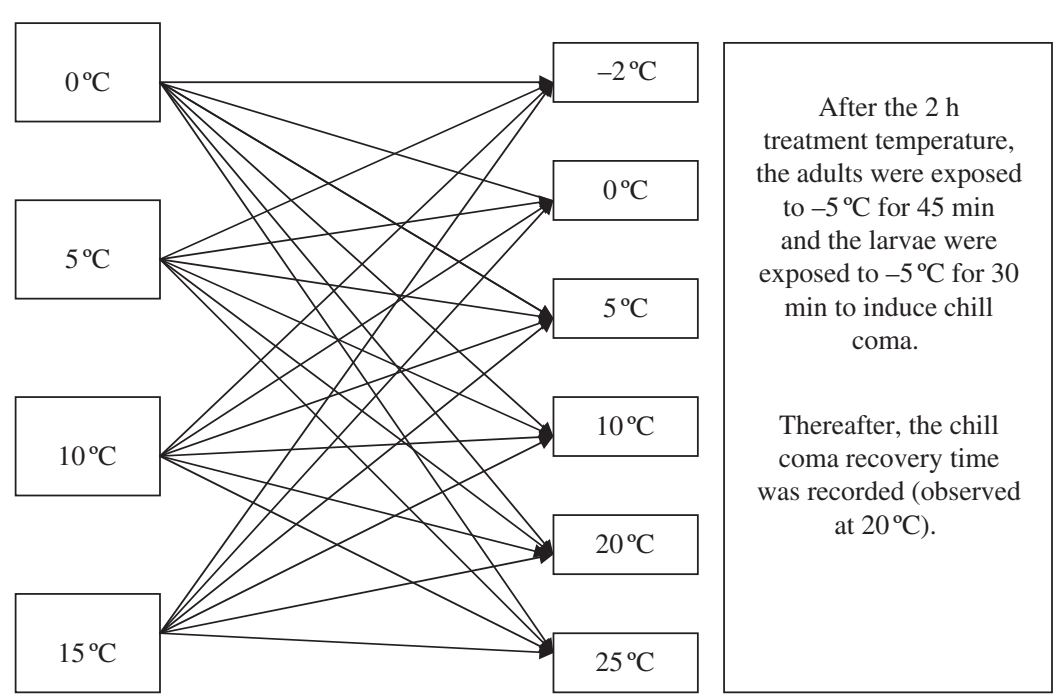


temperatures has an effect on the chill coma recovery time following exposure to a similar range of test temperatures. However, survival after seven days was very low if acclimation temperatures above $15{ }^{\circ} \mathrm{C}$ were used, although short-term exposures $(24 \mathrm{~h})$ to temperatures as high as $28{ }^{\circ} \mathrm{C}$ had little effect on either stage (see also Klok \& Chown 2001 for short-term data). In consequence, the high temperature treatments were higher than the high temperature acclimation. Moreover, we were also interested in the extent to which the term 'particular environment' as used in the definition of the beneficial acclimation hypothesis (Leroi et al. 1994) means a narrowly defined test temperature or a somewhat broader test temperature range. In consequence, a range of test temperatures broader than that of the acclimation temperatures was used.

Twenty individuals from each life stage were randomly selected from more than one jar from a given acclimation temperature and placed into $40 \mathrm{~mL}$ plastic vials (five individuals per vial). After sorting (c. $10 \mathrm{~min}$ at a room temperature of $c .15^{\circ} \mathrm{C}$ ), the vials were placed in a plastic bag inside a water bath set at one of the six treatment temperatures (Grant Instruments, Cambridge, UK water bath models LTC 12, LTD6, G150/R4 and G150/R5 were used). Temperatures inside the vials were monitored by placing a thermochron iButton (Model DS1921) inside a fifth plastic vial. The latter confirmed that the selected temperatures remained within $0.5{ }^{\circ} \mathrm{C}$ of the target.

\section{Chill coma recovery time determinations}

Chill coma recovery time is now widely accepted as an ecologically relevant measure of resistance to low temperature (Gibert et al. 2001; Hoffmann et al. 2003), and is defined as the time it takes for an individual to recover at a higher temperature from chill coma to normal activity. In this study, following their respective $2 \mathrm{~h}$ treatments, vials were directly placed into a Grant LTD6 water bath set at $-5{ }^{\circ} \mathrm{C}$. After 30 and $45 \mathrm{~min}$, respectively, the vials containing larvae and those containing adults were removed from the water bath and the individuals quickly tipped into Petri dishes, which in turn were placed into a glass-fronted LabCon temperature-controlled cabinet set at $20^{\circ} \mathrm{C}$ (total handling time $c .<15 \mathrm{~s}$ ). By inspection through the glass door, the time elapsed from when a vial was removed from the water bath to when an individual started to walk in a coordinated manner was recorded as the chill coma recovery time for that individual.

\section{Thermal preferences}

Thermal preference data for adults and larvae were gathered by placing groups of 10-20 adults or larvae on a linear thermal preference gradient (length $75 \mathrm{~cm}$, temperature range $c .-1$ to $+16{ }^{\circ} \mathrm{C}, 2-4 \mathrm{~h}$ settling time with no light), and determining the temperature preference of each individual (see Supporting Information for details) based on temperatures of the gradient measured using Type T 36gauge thermocouples logged using an eight channel SQ800 Squirrel data logger. Because adults and larvae are sensitive to disturbance we did not attempt to measure body temperatures directly, but assumed that they were close to the temperature of the gradient given the experimental design and small size of the flies. Additional data on locomotion speed for adults and larvae at $5{ }^{\circ} \mathrm{C}$ was gathered (see Supporting Information for details) to confirm the greater mobility in adult flies. To further assess body temperature variation in the field, larval and adult body temperatures $(\mathrm{Tb})$ were determined over two days at Trypot Beach using an infrared thermometer (see Supporting Information for details).

\section{Statistical analyses}

The most appropriate analytical approach for examining the $\mathrm{BAH}$ and its alternatives is the ordered-factor ANOVA with single-degree-of-freedom orthogonal polynomial contrasts proposed by Huey et al. (1999). In this case, a strong inference approach leads to specific predictions for the form and sign of the linear and quadratic terms in an orderedfactor ANOVA for each of the hypotheses (Table 1). Recovery times were $\log _{10}$ transformed which resulted in normal distributions (an assumption of the ordered

Table 1 The predicted significance and sign of the linear and quadratic effects of acclimation and treatment temperature and their interactions on chill coma recovery time for each of the major acclimation hypotheses (adapted from Deere \& Chown 2006)

\begin{tabular}{|c|c|c|c|}
\hline Hypotheses & Acclimation & Treatment & Interaction \\
\hline Colder is Better (CIB) & $\mathrm{L}+$ & $\mathrm{L}+$ & ns \\
\hline Warmer is Better (HIB) & $\mathrm{L}^{-}$ & $\mathrm{L}^{-}$ & ns \\
\hline $\begin{array}{l}\text { Beneficial } \\
\text { acclimation }(\mathrm{BAH})\end{array}$ & & & $\mathrm{L}^{-/+}$ \\
\hline $\begin{array}{l}\text { Deleterious } \\
\text { acclimation }(\mathrm{DAH})\end{array}$ & & & $\mathrm{Q}^{+}$ \\
\hline No plasticity & n.s. & n.s. & n.s. \\
\hline
\end{tabular}

Support for the colder is better hypothesis will take the form of positive linear terms for acclimation temperature and treatment temperature, but no significant interaction. The converse indicates support for the hotter is better hypothesis, whilst support for the beneficial acclimation hypothesis will take the form of a significant, linear interaction term between acclimation and treatment temperatures. A positive quadratic contrast for the interaction between the acclimation and treatment can be expected for Deleterious Acclimation, because recovery times at the extremes would be slow. No significant linear or quadratic terms for the responses or the interactions is predicted if plasticity is absent. 
factor ANOVA). Data for adults and larvae were analyzed separately using sAs version 9.1 (Littell et al. 2002). Orthogonal polynomials for the unequally spaced treatments were compiled from Robson (1959). Where more than one prediction was supported, the F-values (following Huey et al. 1999; Stillwell \& Fox 2005) were used to assess which hypothesis had the strongest support. This approach was complemented with an estimate of effect size, calculated, for each stage, as the mean deviation (\%) of recovery times of the low $\left(-2,05^{\circ} \mathrm{C}\right)$ and high $(10,20$, $25^{\circ} \mathrm{C}$ ) test temperature groups for each acclimation treatment (i.e. $0,5,10$ and $15^{\circ} \mathrm{C}$ ), from the grand mean recovery time for each stage.

To assess the extent to which adults and larvae differ in the range of temperatures preferred, a two-sample Kolmogorov-Smirnov test was applied. Locomotion speed was compared using one-way analysis of variance, and field body temperatures among stages and days were compared using two-way analysis of variance.

\section{RESULTS}

Larval and adult flies differed considerably in the way in which acclimation affected the response of chill coma recovery time to different temperature treatments (Fig. 3). In the larvae, recovery was faster following exposure to treatment temperatures that were the same as or similar to the acclimation temperature, than where acclimation and treatment temperatures were dissimilar, suggesting that acclimation to a certain temperature enhanced performance at that temperature (Fig. 3a). The significant temperature*treatment temperature interaction term in the ordered-factor ANOVA bears out this finding (Table 2). However, the linear term was also significant and positive, suggesting some support for the 'colder is better' hypothesis. Nonetheless, consideration of the F-values demonstrated the strongest support for the interaction. In addition, the sign and size of the mean effect sizes for the low $(-2,0$ $5{ }^{\circ} \mathrm{C}$ ) and high $\left(10,20,25^{\circ} \mathrm{C}\right)$ test temperature groups changed substantially among the high and low temperature acclimations, providing additional support for the $\mathrm{BAH}$ (Table 3).

By contrast, in the adults, it was clear that acclimation to low temperatures generally resulted in the fastest recovery times irrespective of treatment, with the exception of the 20 and $25{ }^{\circ} \mathrm{C}$ treatments, for which recovery time showed little evidence of consistent variation among acclimation temperatures (Fig. 3b). Although the interaction term in the ordered-factor ANOVA was significant (Table 2), inspection of the F-values suggested that it was much less important than the significant, positive, linear effect of acclimation. It appears that the significant interaction term was almost entirely a consequence of the unvarying response of recovery time to the highest treatment temperatures. The change in the sign and mean size of the recovery time differences (Table 3 ) bears out this finding. At the low $\left(0,5{ }^{\circ} \mathrm{C}\right)$ acclimation temperatures, both the high and low test temperature groups had negative deviations from the overall mean, whereas at the high $\left(10,15^{\circ} \mathrm{C}\right)$ acclimations, the opposite was found, though the effect sizes were variable among test temperature groups in both cases.

The more mobile adults (adult locomotion speed at $5^{\circ} \mathrm{C}=2.02 \pm 0.07 \mathrm{~cm} \mathrm{~s}^{-1}$, larvae $0.06 \pm 0.06 \mathrm{~cm} \mathrm{~s}^{-1}$, $\left.\mathrm{F}_{(1,18)}=402.5, P<0.0001\right)$ typically preferred a narrower range of temperatures than did larvae, as was clear from the significant differences among the overall distribution of individuals along the temperature gradient (Fig. 4, K-S test $P<0.001$, see also Supporting Information). In the field, larval body temperatures tended to be more variable than those of the adults (day, stage and their interaction term were all significant in the two-way ANOVA), although only relatively cool days could be investigated (see Supporting Information for full results).

\section{DISCUSSION}

Using protocols that have previously been applied largely to analyses of developmental plasticity (Wilson \& Franklin 2002; Stillwell \& Fox 2005), we have shown substantial differences among life stages in the extent to which acclimation is beneficial. In larvae of Paractora dreuxi acclimation to low temperature typically improved performance following exposure to low temperatures, but not high temperatures, and vice versa. That is, acclimation is beneficial (Leroi et al. 1994; Huey \& Berrigan 1996). Although some indication of better performance following exposure to a low temperature was found in the form of the positive, linear effect of acclimation temperature (i.e. evidence for the 'colder is better' hypothesis), the effect was much weaker than that of the interaction between treatment and acclimation temperature. By contrast, in the adults, acclimation to low temperatures typically resulted in the shortest chill coma recovery time and therefore the best performance following most treatment temperatures. However, firm support for the 'colder is better' hypothesis has to be tempered by the absence of an acclimation effect on exposures to 20 and $25^{\circ} \mathrm{C}$. Nonetheless, it is clear that the stages differ substantially in the extent to which acclimation can be considered beneficial, and in a direction in keeping with the predictions of the Bogert effect (Huey et al. 2003). That is, highly mobile adults, which typically prefer low temperatures, perform best following exposure to a low temperature, whilst the less 
(a)

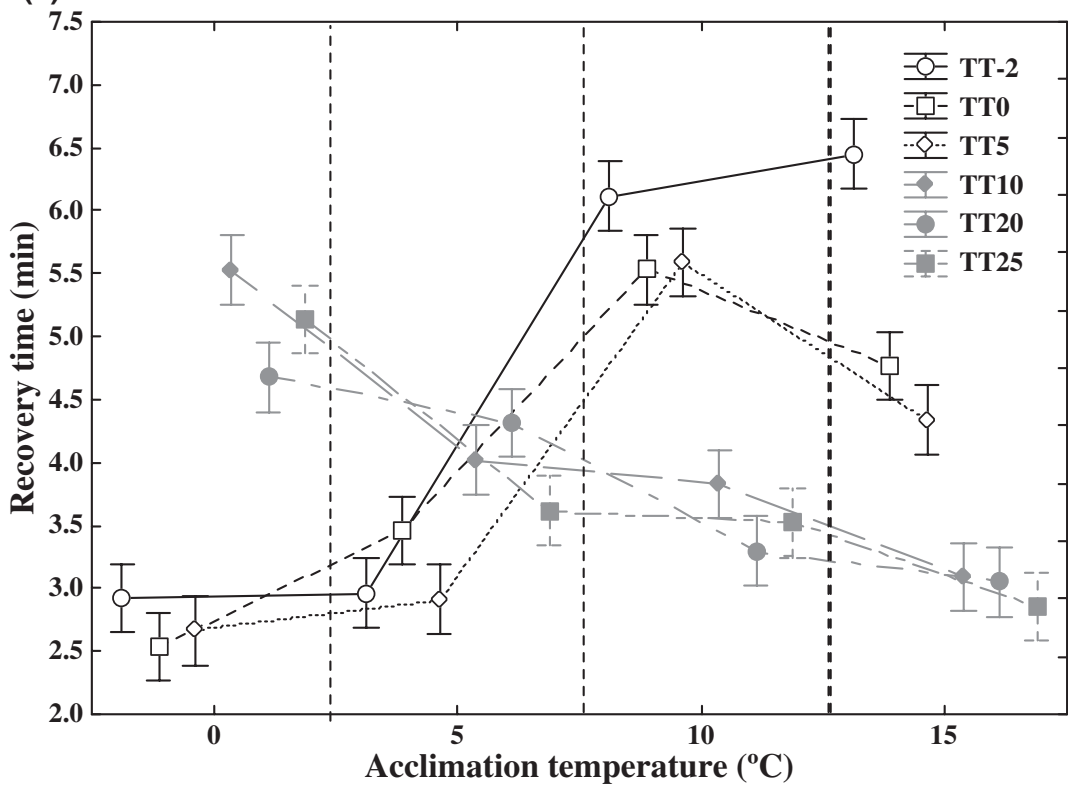

(b)

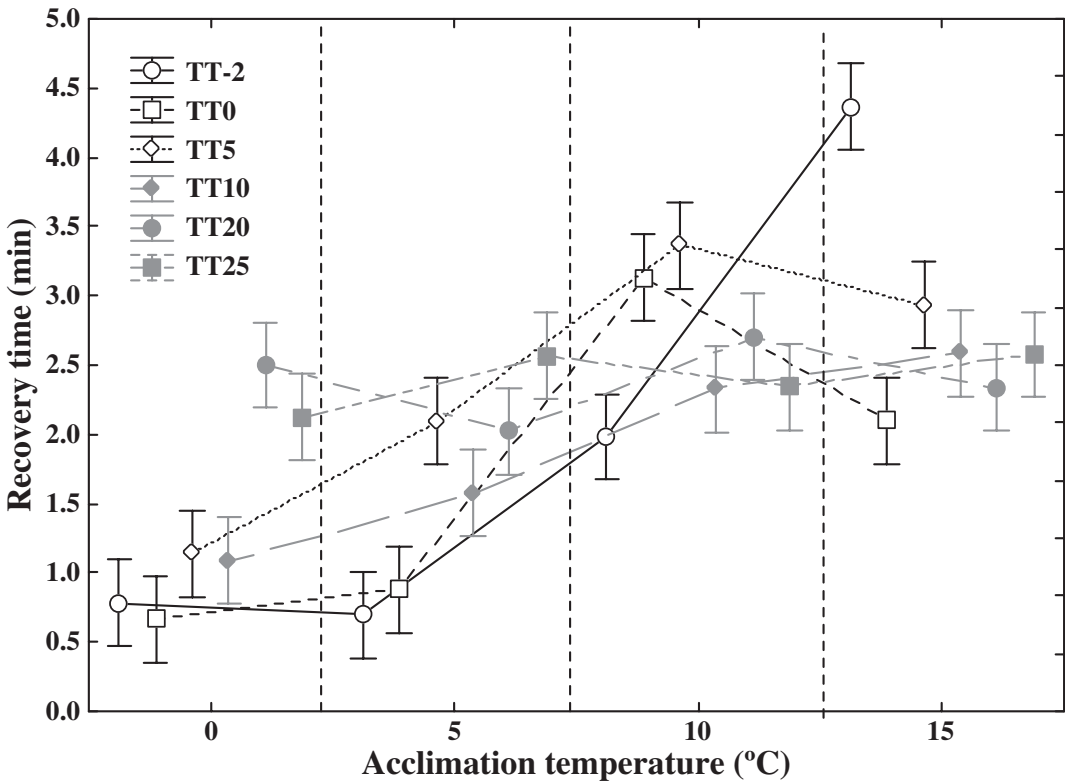

Figure 3 Mean $( \pm$ SE) chill coma recovery times (minutes) in Paractora dreuxi larvae (a) and adults (b) after a 7 -day acclimation at 0 , 5,10 and $15^{\circ} \mathrm{C}$ with $2 \mathrm{~h}$ treatments $(-2,0$, 5, 10, 20 and $\left.25^{\circ} \mathrm{C}\right)$. The acclimation temperatures are provided along the $\mathrm{x}$-axis, and recovery times at each of the test temperatures (TT) indicated using a different symbol. To assist with interpretation of the figure, lower test temperature responses are indicated with open symbols and higher test temperature responses with closed symbols. mobile larvae, which have a broader thermal preference, and typically have to endure temperatures of the kelp frond on which they feed (see also Crafford \& Scholtz 1987; Klok \& Chown 2001) have physiological strategies which enable them to remain active irrespective of previous exposures. Thus, just as behaviour is an important mediator of adaptation, so too might it be an important arbiter of adaptive phenotypic plasticity.

If behavioural responses are important in determining the extent to which a given environmental cue might result in adaptive plasticity, previous work should have documented it. So far as we could ascertain, this has not been done, probably for four main reasons. First, much of the original physiological literature on acclimation is concerned with longer-term responses to seasonal environmental change (e.g. Prosser 1986). Although behavioural differences among stages might have an influence on their response to the seasonally changing environment, typically these environmental changes are so profound that any stage overwintering is likely to be exposed to them. Moreover, often only a single stage overwinters, making comparisons among stages non-sensical or impossible $(P$. dreuxi has overlapping generations and stages all year round - see Supporting Information). Second, even where short-term responses 
Table 2 Outcomes of the ordered-factor ANOVA with orthogonal polynomial contrasts for the effects of acclimation and treatment temperature on $\log _{10}$ chill coma recovery times

\begin{tabular}{lrrrrlll}
\hline & DF & SS & MS & F & P & Coefficient \\
\hline Larvae & & & & & & \\
Acclimation & 3 & 0.77 & 0.26 & 16.98 & $<0.0001$ & 0.21 \\
Treatment & 5 & 0.30 & 0.06 & 4.02 & 0.0014 & \\
Interaction (1) & $\mathbf{1 5}$ & $\mathbf{5 . 4 8}$ & $\mathbf{0 . 3 7}$ & $\mathbf{2 4 . 1 1}$ & $<\mathbf{0 . 0 0 0 1}$ & \\
Interaction (q) & 1 & 0.01 & 0.01 & 0.44 & $>0.05$ & \\
& & & & & & \\
Adults & & & & & & \\
Acclimation & $\mathbf{3}$ & $\mathbf{1 1 . 2 5}$ & $\mathbf{3 . 7 5}$ & $\mathbf{5 7 . 6 8}$ & $<\mathbf{0 . 0 0 0 1}$ & $\mathbf{1 . 3 3 5}$ \\
Treatment & 5 & 8.82 & 1.76 & 27.15 & $<0.0001$ & \\
Interaction (1) & 15 & 7.13 & 0.48 & 7.31 & $<0.0001$ & \\
Interaction (q) & 1 & 0.18 & 0.18 & 2.74 & $>0.05$ & \\
\hline
\end{tabular}

The main effects and the linear and quadratic interactions contrasts are shown. The effect with the largest F-value is shown in bold.

were examined, studies were often restricted to a single stage or the experimental design and analysis was insufficient to allow formal comparisons among stages. This does not mean that ontogenetic differences in physiology have not been explored (see Spicer \& Gaston 1999; Hoffmann et al. 2003; Chown \& Nicolson 2004), but rather that explicit tests of differences in acclimation response are not commonly undertaken. Third, in more recent, rigorous studies, multiple life stages have typically been used in the context of investigations of developmental plasticity (Wilson \& Franklin 2002), rather than in comparisons of acclimation affects among stages. Alternatively the effects of developmental plasticity and of acclimation in the adult stage have been
Table 3 Mean effect sizes and their signs for the low $\left(-2,0,5{ }^{\circ} \mathrm{C}\right)$ and high $\left(10,20,25^{\circ} \mathrm{C}\right)$ test temperature groups for each acclimation treatment (i.e. $0,5,10$ and $15^{\circ} \mathrm{C}$ ), calculated as mean deviation from the grand mean recovery time of each acclimation by test temperature group

\begin{tabular}{llrr}
\hline & & \multicolumn{2}{c}{$\begin{array}{l}\% \text { deviation from } \\
\text { grand mean for } \\
\text { each stage }\end{array}$} \\
\cline { 3 - 4 } Acclimation & Test temperature & Larvae & Adults \\
temperature $\left({ }^{\circ} \mathrm{C}\right)$ & groups $\left({ }^{\circ} \mathrm{C}\right)$ & -33.1 & -59.3 \\
\hline 0 & Low $(-2,0,5)$ & 26.3 & -10.3 \\
0 & High $(10,20,25)$ & -23.2 & -42.2 \\
5 & Low $(-2,0,5)$ & -1.7 & -3.1 \\
5 & High $(10,20,25)$ & 41.9 & 33.3 \\
10 & Low $(-2,0,5)$ & -12.4 & 15.6 \\
10 & High $(10,20,25)$ & 28.0 & 47.8 \\
15 & Low $(-2,0,5)$ & -26.0 & 17.9 \\
15 & High $(10,20,25)$ & & \\
\hline
\end{tabular}

compared (Zeilstra \& Fischer 2005; Terblanche \& Chown 2006), or the effects of hardening in one stage on tolerance in another have been assessed (Crill 1991; Krebs \& Loeschcke 1995; Hercus et al. 2000). Even in assessments of the complex interactions among hardening and acclimation, life stage is rarely considered (e.g. Rako \& Hoffmann 2006). Finally, perhaps the utility of behavioural differences among life stages for assessing the conditions under which adaptive phenotypic plasticity might evolve has simply escaped notice given the debates that have so far occupied the field. Irrespective of the reason, it is clear that behaviour forms one of the major links between an environmental cue and the organismal response (Huey 1991; Huey et al. 2003),
Figure 4 Frequency distributions of preferred body temperatures of larval and adult Paractora dreuxi determined using a linear thermal preference gradient. Note the decline in numbers of adults, but not larvae, that show a preference for temperatures on the gradient above $6{ }^{\circ} \mathrm{C}$ (see also Supporting Information).
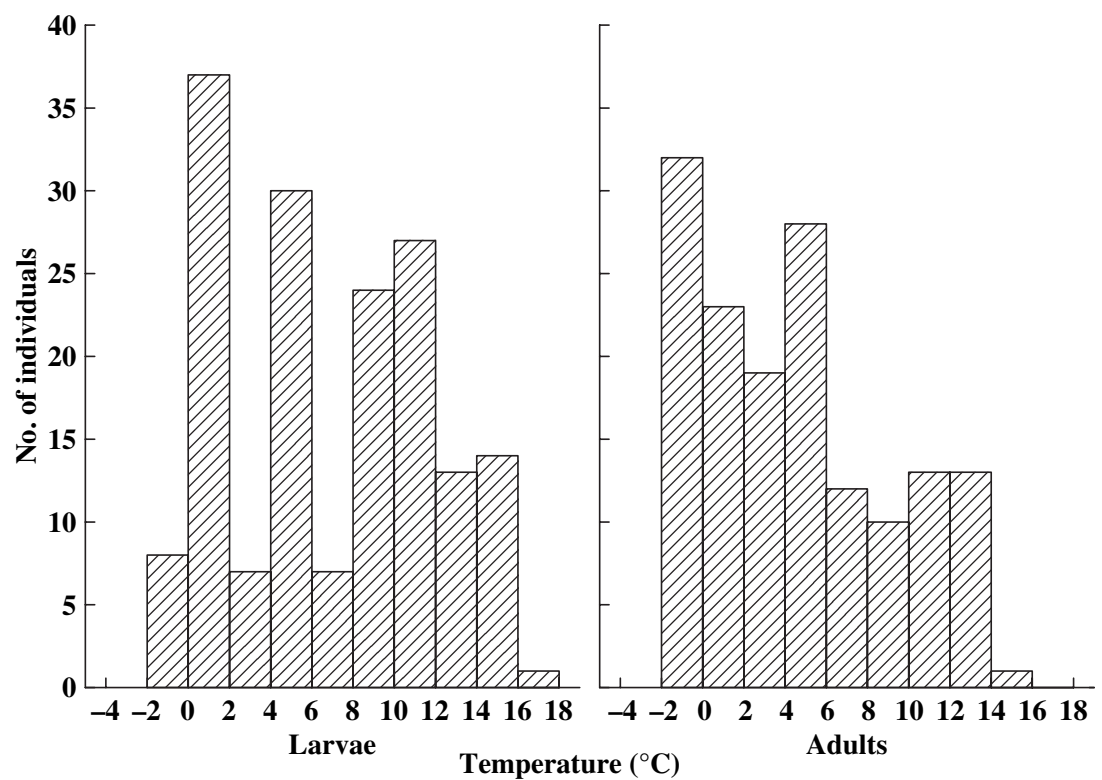

Temperature $\left({ }^{\circ} \mathbf{C}\right)$ 
and should therefore have a major influence on the extent to which plasticity might be shown, and the form that the plasticity takes.

Another important, though likewise unexplored link between an environmental cue and the organismal response is the sensing system. At least in the insects investigated to date, it appears that small differences in temperature (as little as $0.1^{\circ} \mathrm{C}$ ) can be precisely sensed (Chown \& Terblanche 2007). However, how this precision in sensing is translated into a physiological response to the thermal environment, and what the implications thereof are for assessing adaptive phenotypic plasticity are less apparent (Chown \& Terblanche 2007). The responses of the $P$. dreuxi larvae to the acclimation and temperature treatments make clear the significance of this question. Following acclimation to $0{ }^{\circ} \mathrm{C}$ and to $5{ }^{\circ} \mathrm{C}$, the fastest chill coma recovery times were found in the $-2,0$ and $5{ }^{\circ} \mathrm{C}$ treatments, with little variance among them (Fig. 3a). Likewise, following acclimation to 10 and $15{ }^{\circ} \mathrm{C}$, the fastest recovery times were found for the 10 , 20 and $25{ }^{\circ} \mathrm{C}$ treatments. Thus, how broadly the term 'particular environment' in the definition of beneficial acclimation - 'acclimation to a particular environment gives an organism a performance advantage in that environment over another organism that has not had the opportunity to acclimate to that particular environment' (Leroi et al. 1994; see also Wilson \& Franklin 2002) - is to be interpreted is not obvious. Clearly, organisms are capable of discerning subtle changes in the environment and responding physiologically to them over fine temporal scales (Kelty \& Lee 2001; Worland \& Convey 2001). However, it is also apparent that the response need not be anywhere near as fine-tuned (Sinclair et al. 2003; Rako \& Hoffmann 2006; Terblanche et al. 2006). Thus, despite their ability to sense fine changes in the thermal environment, organisms might respond to them much more broadly (see also Good 1993). In consequence, for some organisms, narrow restriction of the term "particular environment might be appropriate, whilst in others the term might refer to a broader range of temperatures or other conditions. When either circumstance might apply is far from clear because so few studies have sought to examine this question explicitly.

\section{ACKNOWLEDGEMENTS}

Logistic support in the field was provided by the South African National Antarctic Program and the 2006-2008 Marion Island relief teams, whose members also assisted with fly collection. We thank Jen Lee for independently assessing thermal preferences during the thermal preference experiments, John Terblanche for help with analyses, and Sue Jackson, Ray Huey, two anonymous referees, and Steve Beissinger for comments on previous versions of the manuscript.

\section{REFERENCES}

Bartholomew, G.A. (1958). The role of physiology in the distribution of terrestrial vertebrates. In: Zoogeography (Publ. No. 51) (ed. Hubbs, C.L.). American Association for the Advancement of Science, Washington, D.C., pp. 81-95.

Bogert, C.M. (1949). Thermoregulation in reptiles, a factor in evolution. Evolution, 3, 195-211.

Bradshaw, A.D. (1972). Some of the evolutionary consequences of being a plant. Evol. Biol., 5, 25-47.

Chown, S.L. \& Nicolson, S.W. (2004). Insect Physiological Ecology. Mechanisms and Patterns. Oxford University Press, Oxford.

Chown, S.L. \& Terblanche, J.S. (2007). Physiological diversity in insects: ecological and evolutionary contexts. Adv. Insect Physiol., 33, 50-152.

Crafford, J.E. (1984). Life cycle and kelp consumption of Paractora dreuxi mirabilis (Diptera: Helcomyzidae): a primary decomposer of stranded kelp on Marion Island. S. Afr. J. Antarct. Res., 14, 18-22.

Crafford, J.E. \& Scholtz, C.H. (1987). Phenology of stranded kelp degradation by the kelp fly Paractora dreuxi mirabilis (Helcomyzidae) at Marion Island. Polar Biol., 7, 289-294.

Crill, W.D. (1991). High parental and developmental temperatures increase heat resistance of adult Drosophila melanogaster. Am. Zool., $31,58 \mathrm{~A}$.

Deere, J.A. \& Chown, S.L. (2006). Testing the beneficial acclimation hypothesis and its alternatives for locomotor performance. Am. Nat., 168, 630-644.

Deere, J.A., Sinclair, B.J., Marshall, D.J. \& Chown, S.L. (2006). Phenotypic plasticity of thermal tolerances in five oribatid mite species from sub-Antarctic Marion Island. J. Insect Physiol., 52, 693-700.

Dillon, M.E., Cahn, L.R.Y. \& Huey, R.B. (2007). Life history consequences of temperature transients in Drosophila melanogaster. J. Exp. Biol., 210, 2897-2904.

Feder, M.E., Blair, N. \& Figueras, H. (1997). Oviposition site selection: unresponsiveness of Drosophila to cues of potential thermal stress. Anim. Behav., 53, 585-588.

Feder, M.E., Bennett, A.F. \& Huey, R.B. (2000). Evolutionary physiology. Ann. Rev. Ecol. Syst., 31, 315-341.

Ghalambor, C.K., McKay, J.K., Carroll, S.P. \& Reznick, D.N. (2007). Adaptive versus non-adaptive phenotypic plasticity and the potential for contemporary adaptation in new environments. Funct. Ecol., 21, 394-407.

Gibert, P., Moreteau, B., Petavy, G., Karan, D. \& David, J.R. (2001). Chill-coma tolerance, a major climatic adaptation among Drosophila species. Evolution, 55, 1063-1068.

Gilchrist, G.W. \& Huey, R.B. (2001). Parental and developmental temperature effects on the thermal dependence of fitness in Drosophila melanogaster. Evolution, 55, 209-214.

Good, D.S. (1993). Evolution of behaviours in Drosopbila melanogaster in high temperatures: genetic and environmental effects. J. Insect Physiol., 39, 537-544.

Hercus, M.J., Berrigan, D., Blows, M.W., Magiafoglou, A. \& Hoffmann, A.A. (2000). Resistance to temperature extremes between and within life cycle stages in Drosophila serrata, D. birchii and their hybrids: intraspecific and interspecific comparisons. Biol. J. Linn. Soc., 71, 403-416.

Hertz, P.E. \& Huey, R.B. (1981). Compensation for altitudinal changes in the thermal environment by some Anolis lizards on Hispaniola. Ecology, 62, 515-521. 
Hoffmann, A.A. \& Watson, M. (1993). Geographical variation in the acclimation responses of Drosophila to temperature extremes. Am. Nat., 142, S93-S113.

Hoffmann, A.A., Sørensen, J.G. \& Loeschcke, V. (2003). Adaptation of Drosophila to temperature extremes: bringing together quantitative and molecular approaches. J. Thermal Biol., 28, 175-216.

Huey, R.B. (1991). Physiological consequences of habitat selection. Am. Nat., 137, s91-s115.

Huey, R.B. \& Berrigan, D. (1996). Testing evolutionary hypotheses of acclimation. In: Phenotypic and Evolutionary Adaptation to Temperature (eds Johnston, I.A. \& Bennett, A.F.). Cambridge University Press, Cambridge, pp. 205-237.

Huey, R.B., Berrigan, D., Gilchrist, G.W. \& Herron, J.C. (1999). Testing the adaptive significance of acclimation: a strong inference approach. Am. Zool., 39, 323-336.

Huey, R.B., Hertz, P.E. \& Sinervo, B. (2003). Behavioral drive versus behavioral inertia in evolution: a null model approach. Am. Nat., 161, 357-366.

Kelty, J.D. \& Lee, R.E. (2001). Rapid cold-hardening of Drosophila melanogaster (Diptera: Drosophilidae) during ecologically based thermoperiodic cycles. J. Exp. Biol., 204, 1659-1666.

Kingsolver, J.G. \& Huey, R.B. (1998). Evolutionary analyses of morphological and physiological plasticity in thermally variable environments. Am. Zool., 38, 545-560.

Klok, C.J. \& Chown, S.L. (2001). Critical thermal limits, temperature tolerance and water balance of a sub-Antarctic kelp fly, Paractora dreuxi (Diptera: Helcomyzidae). J. Insect Physiol., 47, 95-109.

Krebs, R.A. \& Loeschcke, V. (1995). Resistance to thermal stress in preadult Drosophila buzzatii: variation among populations and changes in relative resistance across life stages. Biol. J. Linn. Soc., $56,517-531$.

Kristensen, T.N., Loeschcke, V. \& Hoffmann, A.A. (2007). Can artificially selected phenotypes influence a component of field fitness? Thermal selection and fly performance under thermal extremes. Proc. R. Soc. B, 274, 771-778.

Leroi, A.M., Bennett, A.F. \& Lenski, R.E. (1994). Temperature acclimation and competitive fitness: an experimental test of the beneficial acclimation assumption. Proc. Natnl. Acad. Sci. U.S.A., 91, 1917-1921.

Levins, R. (1968). Evolution in Changing Environments. Princeton University Press, Princeton.

Littell, R.C., Stroup, W.W. \& Freund, R.J. (2002). SAS for Linear Models. SAS Institute Inc, Cary, NC, USA.

Loeschcke, V. \& Hoffmann, A.A. (2007). Consequences of heat hardening on a field fitness component in Drosophila depend on environmental temperature. Am. Nat., 169, 175-183.

Parsons, P.A. (1998). Behavioral variability and limits to evolutionary adaptation under stress. Adv. Stud. Behav., 27, 155-180.

Prosser, C.L. (1986). Adaptational Biology: Molecules to Organisms. Wiley and Sons, New York.

Rako, L. \& Hoffmann, A.A. (2006). Complexity of the cold acclimation response in Drosophila melanogaster. J. Insect Physiol., 52, 94-104.

Robson, D.S. (1959). A simple method for constructing orthogonal polynomials when the independent variable is unequally spaced. Biometrics, 15, 187-191.

Sinclair, B.J., Vernon, P., Klok, C.J. \& Chown, S.L. (2003). Insects at low temperatures: an ecological perspective. Trends Ecol. Evol., 18, 257-262.
Spicer, J.I. \& Gaston, K.J. (1999). Physiological Diversity and its Ecological Implications. Blackwell Science, Oxford.

Stillwell, R.C. \& Fox, C.W. (2005). Complex patterns of phenotypic plasticity: interactive effects of temperature during rearing and oviposition. Ecology, 86, 924-934.

Terblanche, J.S. \& Chown, S.L. (2006). The relative contributions of developmental plasticity and adult acclimation to physiological variation in the tsetse fly, Glossina pallidipes (Diptera, Glossinidae). J. Exp. Biol., 209, 1064-1073.

Terblanche, J.S., Klok, C.J., Krafsur, E.S. \& Chown, S.L. (2006). Phenotypic plasticity and geographic variation in thermal tolerance and water loss of the tsetse Glossina pallidipes (Diptera: Glossinidae): implications for distribution modelling. Am. J. Trop. Med. Hyg., 74, 786-794.

Terblanche, J.S., Marais, E. \& Chown, S.L. (2007). Stage-related variation in rapid cold hardening as a test of the environmental predictability hypothesis. J. Insect Physiol., 53, 455465.

Van Kleunen, M. \& Fischer, M. (2007). Progress in the detection of costs of phenotypic plasticity in plants. New Phytol., 176, 727730 .

Wilson, R.S. \& Franklin, C.E. (2002). Testing the beneficial acclimation hypothesis. Trends Ecol. Evol., 17, 66-70.

Worland, M.R. \& Convey, P. (2001). Rapid cold hardening in Antarctic microarthropods. Funct. Ecol., 15, 515-524.

Zeilstra, I. \& Fischer, K. (2005). Cold tolerance in relation to developmental and adult temperature in a butterfly. Physiol. Entomol., 30, 92-95.

\section{SUPPORTING INFORMATION}

Additional Supporting Information may be found in the online version of this article.

A word document containing the following:

\section{- Supplementary Methods}

- Figure S1 The thermal preference gradient used in the present study.

- Figure S2 Temperatures immediately below a kelp frond (kelp) in the wrack, and at 5, 25 and $43 \mathrm{~cm}$ depths into the pebble substrate on Trypot Beach, recorded using Thermochron DS1922H i-button dataloggers $\left(0.2^{\circ} \mathrm{C}\right.$ resolution) on 5-16 April 2008.

- Figure S3 Trypot Beach at Marion Island. Kelp flies typically occupy the kelp-covered area of the beach along the shore.

- Figure S4 Moulting elephant seals occupying the study site at Trypot Beach on a sunny afternoon.

\section{- Supplementary Results}

- Figure S5 Median, quartile range and minima and maxima of the preferred body temperatures of adults and larvae of Paractora dreuxi.

- Table S1 Outcome of a two-way analysis of variance with day and stage (adults vs. larvae) as the categorical factors.

- Figure S6 Body temperatures ( $\pm 95 \%$ confidence intervals) of larval and adult Paractora dreuxi and 
substrate rock surface temperatures at Trypot Beach on two relatively cool days (6th and 7 th of April 2008).

\section{- References}

Please note: Blackwell Publishing are not responsible for the content or functionality of any supporting materials supplied by the authors. Any queries (other than missing material) should be directed to the corresponding author for the article.

\section{Editor, Steve Beissinger}

Manuscript received 25 January 2008

First decision made 25 February 2008

Manuscript accepted 20 May 2008 